University of Massachusetts Amherst ScholarWorks@UMass Amherst

Masters Theses 1911 - February 2014

1978

\title{
Hypothalamic hypoactivity prevented but not reversed by subdiaphragmatic vagotomy.
}

Ricardo Eng

University of Massachusetts Amherst

Follow this and additional works at: https://scholarworks.umass.edu/theses

Eng, Ricardo, "Hypothalamic hypoactivity prevented but not reversed by subdiaphragmatic vagotomy." (1978). Masters Theses 1911 February 2014. 1490.

Retrieved from https://scholarworks.umass.edu/theses/1490

This thesis is brought to you for free and open access by ScholarWorks@UMass Amherst. It has been accepted for inclusion in Masters Theses 1911 -

February 2014 by an authorized administrator of ScholarWorks@UMass Amherst. For more information, please contact

scholarworks@library.umass.edu. 
UNASS/AMHERST

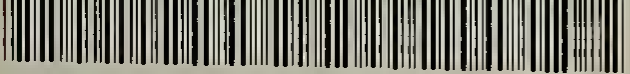

3120066013805643 


\section{HYPOTHALAMIC HYPOACTIVITY PREVENTED BUT NOT REVERSED BY SUBDIAPHRAGMATIC}

VAGOTOMY

\section{A Thesis Presented}

By

RICARDO ENG

Submitted to the Graduate School of the University of Massachusetts in partial fulfillment of the requirements for the degree of

MASTER OF SCIENCE

$$
\text { August } 1978
$$

Psychology Department 


\section{HYPOTHALAMIC HYPOACTIVITY PREVENTED \\ BUT NOT REVERSED BY SUBDIAPHRAGMATIC \\ VAGOTOMY}

A Thesis Presented

By

RICARDO ENG

Approved as to style and content by:

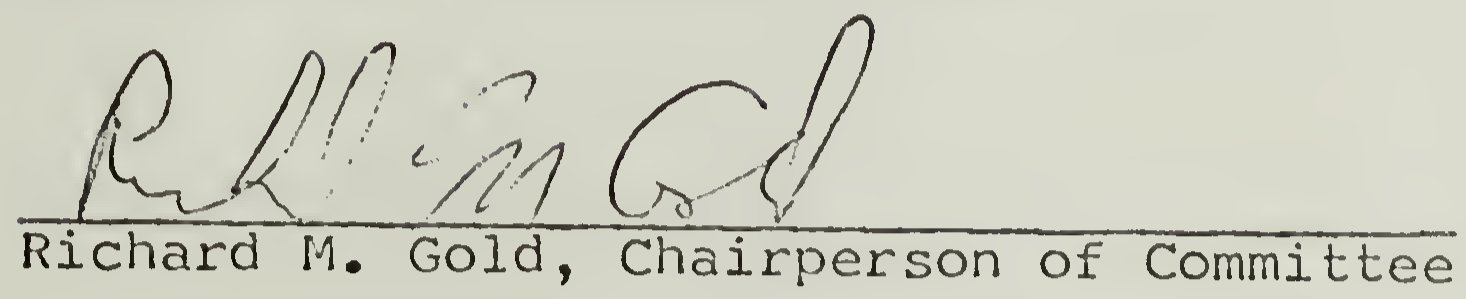

$\frac{\text { Edwand Husch }}{\text { Edward Hirsch, Member }}$

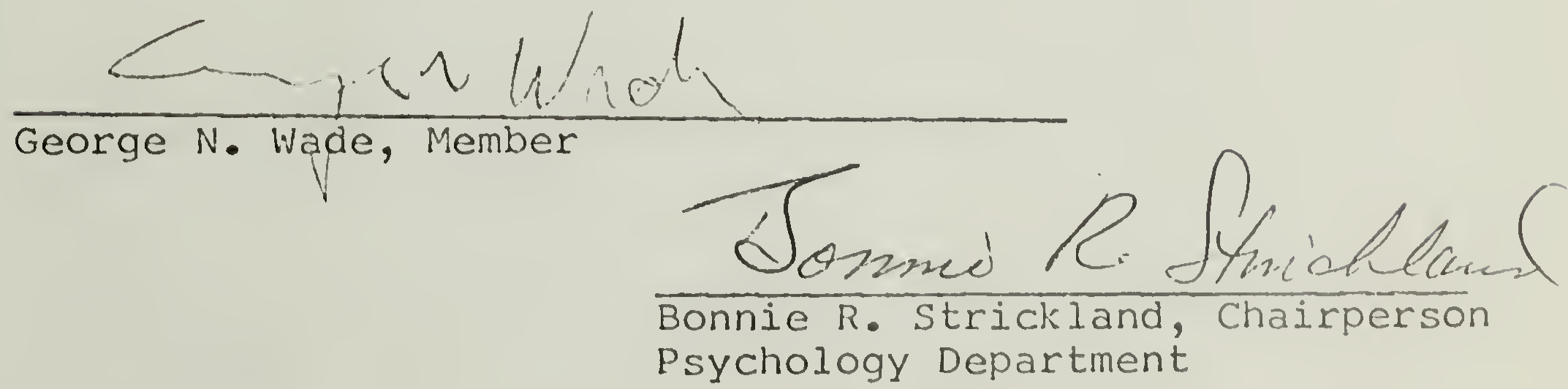




\section{Acknowledgements}

I wish to thank the members of my committee for their guidance and helpful suggestions. I thank sue Rice for her encouragement and moral support during the conduct of the research. Thanks are also due to Paul Sawchenko and Earl simson for their stimulating discussions of the data, and to Jay Alexander for technical assistance. 


\section{Abstract}

Parasagittal hypothalamic knife cuts produce a syndrome which includes obesity and hypoactivity. When the subdiaphragmatic vagi were cut at the same time as the brain cuts were made, both the obesity and the hypoactivity were prevented. This suggested that both the obesity and the hypoactivity are mediated by vagal hyperactivity. In contrast, however, when the subdiaphragmatic vagotomy was done 40-70 days subsequent to the brain cuts, the obesity was reversed, but the hypoactivity persisted. Thus, some aspect of the interoperative period irreversibly prevents the ability of vagotomy to reinstate normal activity levels in the rat. 


\section{Table of Contents}

Acknowledgements . . . . . . . . . . . p. iii Abstract . . . ............. p. p iv Introduction ................ p. 1 Methods . . . . . . . . . . . . p. 3 Results . . . . . . . . . . . . p. 5 Discussion . . . . . . . . . . . . p. 7 Figure 1. . . . . . . . . . p 10 Figure 2. . . . . . . . . . . . p. 11 Figure 3... • . . . . . . . . p. 12 References . . . . . . . . . . p. 13 
vi

List of Figures

Figure 1............. p. 10

Figure 2.................. p 11

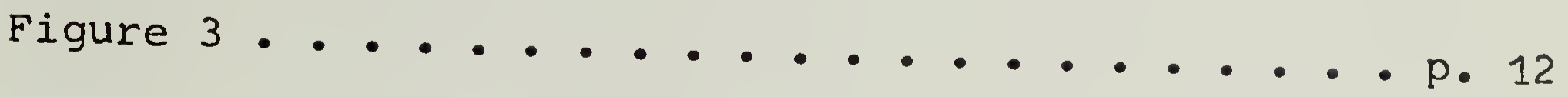




\section{Introduction}

In the rat, lesions in the medial hypothalamus (MH) produce a complex syndrome whose components include: hyperphagia and obesity (Hetherington and Ranson, 1940), hyperdipsia (Sclafani and Grossman, 1971), decreased linear growth and growth hormone secretion (Bernardis and Frohman, 1970), gonadal dysfunction (Greer, 1953), hyperinsulinemia (Hales and Kennedy, 1964; Han and Frohman, 1970; Hustvedt

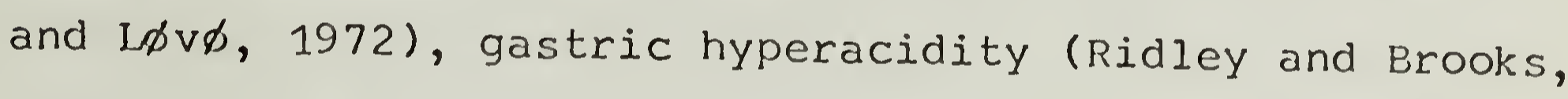
1965), slowed gastric clearance (Ralph and Sawchenko, 1978), hyperreactivity (Grossman, 1966, 1972; Sclafani et al., 1970), and dietary finickiness (Graff and Stellar, 1962). In addition, the syndrome includes decrements in spontaneous activity in running wheels (Brooks, 1946; Gladfelter and Brobeck, 1962; Hetherington and Ranson, 1942; Kennedy and Mitra, 1963; Kennedy, 1964), as well as in stabilimeters (Teitelbaum, 1957).

Parasagittal hypothalamic knife cuts also produce hyperphagia and obesity, but some of the other features of the syndrome are avoided, and therefore are presumed to be due to the non-selective nature of electrolytic lesions as opposed to the more discrete damage that can be inflicted with knife cuts. For example, by using knife cuts, the 
hyperdipsia (Gold et al., 1977), decreased growth and growth hormone levels (Gold and Kapatos, 1975), gonadal dysfunction (Paxinos, 1974; Sclafani, 1971), hyperreactivity (Paxinos, 1974), and finickiness (Gale and Sclafani, 1977; Sclafani et al., 1976) are avoided, or attenuated, whereas the presumably vagally mediated functions: hyperinsulinemia (Tannenbaum et al., 1974), gastric hyperacidity (Sawchenko and Gold, in preparation), and slowed gastric clearance (Sawchenko, unpublished) persist. Hypoactivity also has been shown to persist after obesifying knife cuts (Sclafani, 1971; Eng, unpublished), despite the absence of any clear link between activity and vagal function.

Subdiaphragmatic vagotomy abolishes both hypothalamic lesion obesity (Inoue and Bray, 1977; Porte et al., 1973) and hypothalamic knife cut obesity (Sawchenko et al., 1977a). Subdiaphragmatic vagotomy also normalizes the lesion-induced hyperinsulinemia and gastric hyperacidity (Inoue and Bray, 1977; Powley and Opsahl, 1974; Sawchenko etal., 1977a). If the knife cut induced hypoactivity shares a common metabolic etiology with hyperphagia and obesity, then vagotomy simultaneous with knife cuts should prevent both hypoactivity and obesity, and vagotomy sub- 
sequent to knife cuts should reinstate normal weight and activity levels.

Vagally-induced (neurogenic) hyperinsulinemia is most prominently mentioned as a possible cause of the obesity (Powley and Opsahl, 1974), especially since exogenous insulin can produce overeating and obesity (May and Beaton, 1968; Panksepp et al., 1975) and, most interestingly, hypoactivity in running wheels (Campbell and Fibiger, 1970). Furthermore, vagal stimulation has been shown to elicit insulin release, presumably through direct pancreatic beta cell innervation (Porte et al., 1973). We propose that hypothalamic obesity and hypothalamic hypoactivity are both due to disinhibition of a vagal mechanism which disrupts energy balance by increasing anabolic processes which diminish the availability of metabolic fuels for voluntary exercise.

\section{Methods}

Adult female Charles River $C D$ albino rats were housed in Wahmann activity wheels, in an air conditioned $\left(22^{\circ} \mathrm{C}_{\text {. }}\right.$ ) room under a 12:12 light cycle. Purina chow pellets and tap water were available ad libitum.

The preceding day's activity (wheel revolutions) was 
recorded during the last hour of the light period. Body weight was recorded twice a week, and daily food and water intakes were measured periodically. Daily vaginal smears were taken to provide an index of the contribution of gonadal dysfunction to activity changes. A one month period of adaptation to the activity wheels preceded any surgery. All surgery was performed under Nembutal anesthesia $(40 \mathrm{mg} / \mathrm{kg}$, i.p.).

Retracting wire knife cuts were made as previously described (Gold et al., 1977). Bilateral parasagittal cuts were placed $0.9 \mathrm{~mm}$ from the midline at the coronal level of the paraventricular nucleus. These cuts extended $3 \mathrm{~mm}$ rostro-caudally and $3 \mathrm{~mm}$ dorsally from the base of the brain. The correctness of the placements of the knife cuts was verified by two independent blind raters. Brain sections from the rats in the present study were examined along with selected sections from control rats that only received knife cuts and were not exposed to wheels. Some of these control cuts had produced hyperphagia and obesity, and some had not. The raters agreed with each other on all judgments and correctly rated all the sections. All of the data reported in the present study were from rats whose cuts were judged by 
both raters to be sufficient to produce hyperphagia and obesity .

Subdiaphragmatic vagotomies were performed as previously described (Sawchenko et al., 1977b), using a $20 \mathrm{x}$ Zeiss operating microscope. The esophagus was exposed via an abdominal incision, and the branches of the vagus were visualized and cut as they run along the esophagus. This technique ensured the cutting of the hepatic, coeliac, and both gastric branches. Vagotomies were verified by an acute gastric acid secretion method (Powley and Opsahl, 1974) in which the failure to observe an increase in gastric acid secretion in response to electrical stimulation of the cervical vagi was taken as evidence that vagotomy was complete.

Data were statistically analyzed using the two sample Student's t-test, with alpha $=.05$ and $d f=4$ (Spence et al., 1968).

\section{Results}

When vagotomy was performed at the same time as the obesifying hypothalamic knife cuts, the hyperphagia and hypoactivity predicted by the hypothalamic knife cuts alone were not seen (Figure $1, n=4)$. Activity levels 
dipped significantly for a 20 day postoperative period $(p<.05$, one-tailed) and then returned to normal levels $(p<.10)$. The transient decrease in activity was associated with a temporary (1-3 week) disruption of estrous cycling, after which normal cycling resumed.

The normal activity levels were not simply due to the absence of hyperphagia and obesity, because when rats with knife cuts and intact vagi were restricted to preoperative food intakes, they still were hypoactive (Figure 2, $n=4$, $p<.05)$. Subsequently, these rats were free fed for 20 days, which behavioraily confirmed that these knife cuts would produce hyperphagia and obesity $(p<.05)$. Finally, vagotomy on these obese hypoactive rats 70 days after the brain knife cuts reversed the weight gains ( $<.05)$, but, surprisingly, the hypoactivity persisted $(p<.05)$ even as the body weights fell below control levels $(p<.05)$, and despite normal estrous cycling.

Similarly, when rats were not food restricted at all after knife cuts ( 2 on a high fat diet, 3 on pellets), subsequent vagotomy reversed the obesity $(p<.05)$ but not the hypoactivity $(p<.05$, Figure 3$)$. Individual data are presented in Figure 3. Two animals died at times indicated by the crosses. 


\section{Discussion}

It is concluded that hypoactivity in running wheels is an unavoidable consequence of the neurological damage required for hyperphagia and obesity (Gold et al., 1977; Sclafani, 1971; Storlien and Albert, 1972). The hypoactivity and the obesity may share a common etiology since vagotomy can prevent both of these knife cut effects. The data presented suggest that the common etiology of knife cut obesity and hypoactivity is a vagal mechanism, such as hyperinsulinemia. In support of this, exogenous insulin has been shown to both elicit eating (May and Beaton, 1968; Panksepp et al., 1975) and depress running wheel activity (Campbell and Fibiger, 1970). The hyperinsulinemia seen in the $M H$ damaged rat has been correlated with the degree of hyperphagia (Hustvedt and Lbvo, 1972). It is proposed that hyperinsulinemia favors energy storage, and the resulting lack of available metabolic fuels causes hypoactivity. Similarly, a lack of available fuels to receptors may trigger appetite (Friedman and Stricker, 1976). Fuel availability would presumably affect physical endurance (Bergstrom et al., 1967). Unpublished data from this laboratory indicate that rats' swimming endurance (forced exercise) is also decreased by 
obesifying knife cuts but is reinstated by vagotomy.

Gastric distention may have an inhibitory effect on activity via vagal afferents. In the intact brain rat, vagotomy abolishes the suppressive effect of non-nutritive bulk on deprivation induced running (Messing and Campbell, 1971), and changes the pattern of activity such that the normal periods of quiescence following a meal no longer occur (Bash, 1939). Could hypothalamic hypoactivity be due to the gastric distention brought about by excessive food intake (Gold, 1970; Gold et al., 1977; Hetherington and Ranson, 1942) and decreased gastric motility (Ralph and Sawchenko, 1978)? This possibility is unlikely, since preverition of gastric distention by food restriction did nat abolish the hypoactivity in knife cut rats.

The role of the ovaries in running wheel activity and body weight is well known (Wade, 1976). High levels of running wheel activity are associated with estrus (Wang, 1923). Removal of the ovaries results in obesity (Kakolewski et al., 1968) and hypoactivity (Calvin and Sawyer, 1969). In MH lesioned rats, cyclic wheel running and other sex hormone mediated behaviors such as lordosis are abolished, even though normal vaginal cycling resumes (Kennedy and Mitra, 1963). Could hypothalamic obesity 
and hypoactivity be due.to ovarian dysfunction? Probably not. It has been demonstrated that ovarian obesity is separate from hypothalamic knife cut obesity since the obesifying effects of ovariectomy and hypothalamic knife cuts are additive (Gale and Sclafani, 1977). Although hypothalamic damage may cause obesity due in part to disruption of sex hormones (Hennessy and Grossman, 1976), the present knife cut obesity and hypoactivity were probably not caused by gonadal dysfunction, since normal cycling resumed.

The failure of delayed vagotomies to reverse running wheel hypoactivity is perplexing. Some aspect of the 4070 day interoperative period, such as obesity itself or some related hormonal dysfunction, may cause permanent damage, such as pancreatic beta cell hypertrophy (Kennerly and Parker, 1963), that precludes renewed running wheel activity. Vagotomy appears to prevent but not to reverse this damage. Simultaneously operated rats never experience these presumably vagally mediated disorders, whereas rats that get knife cuts 40-70 days before vagotomy do. 


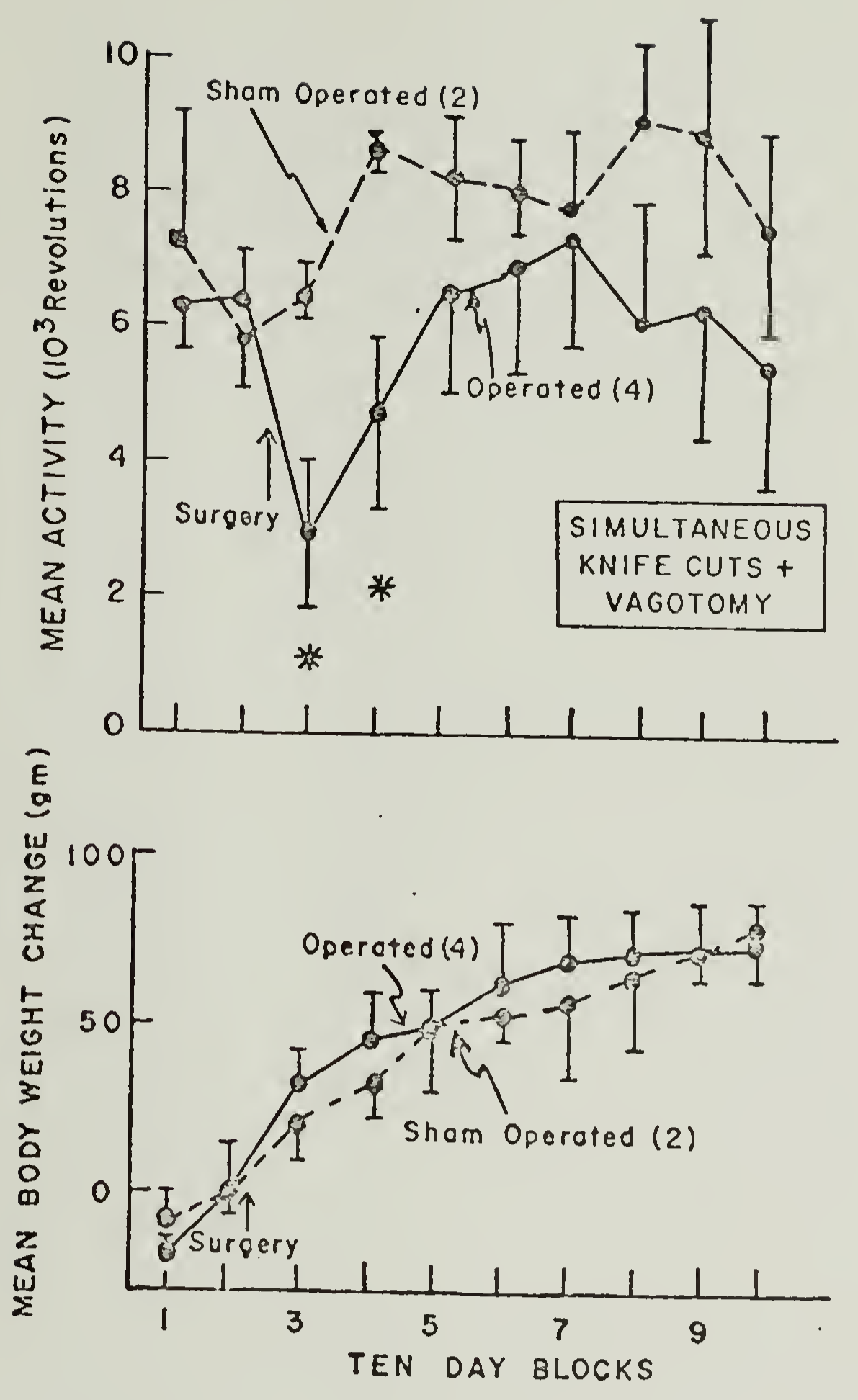

Figure 1: The mean activity ( \pm SEM) and mean body weight change (I SEM) in rats with simultaneous knife cuts and vagotomy. Indicates $p<0.05$. 

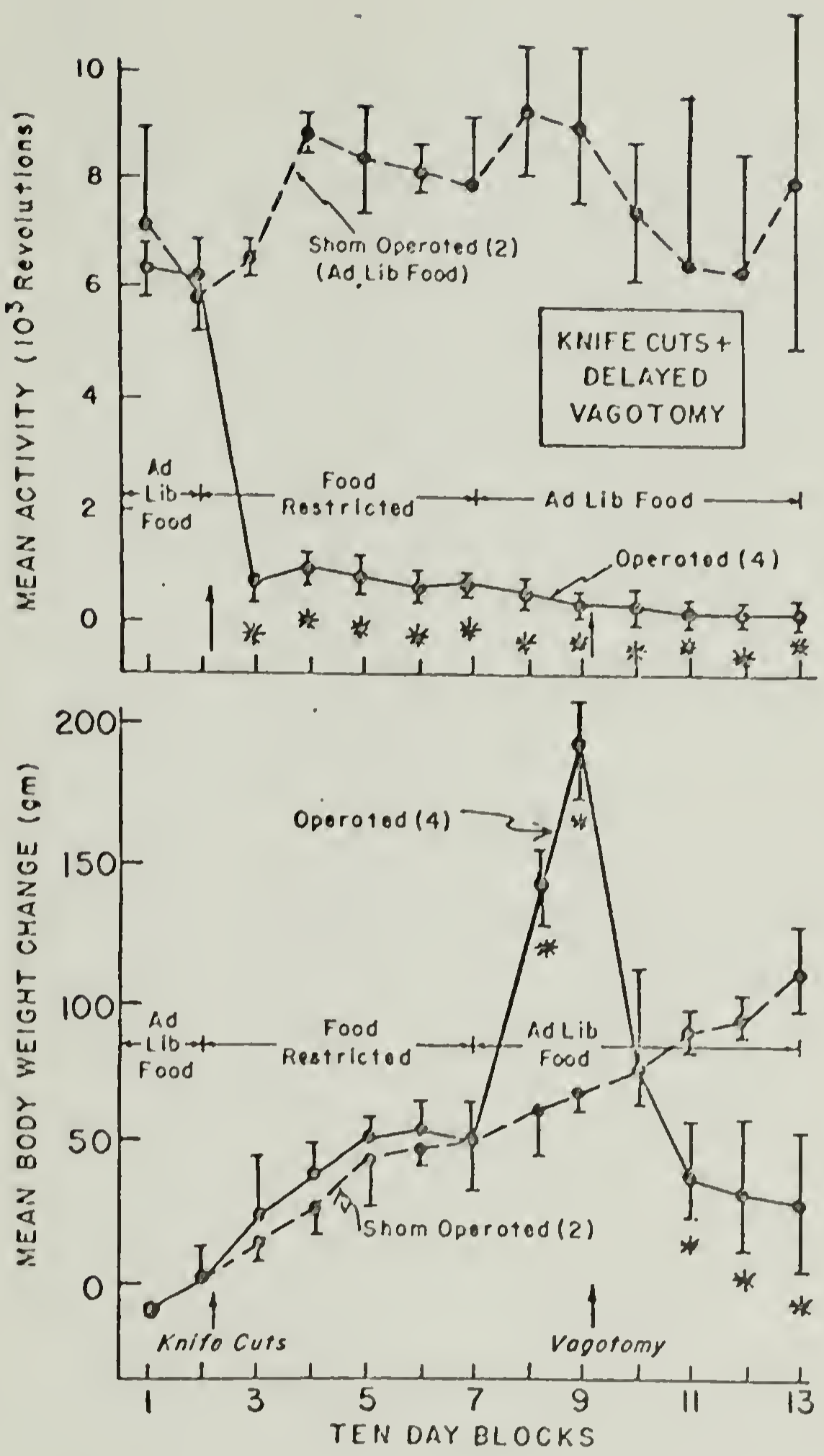

Fiqure 2. The mean activity ( \pm SEM) and mean body weight change ( 1 SEil) in knife cut rats subjected to 50 days food restriction, then ad lib food, followed by vagotomy at 70 days post knife cuts. Indicates $p<0.05$. 


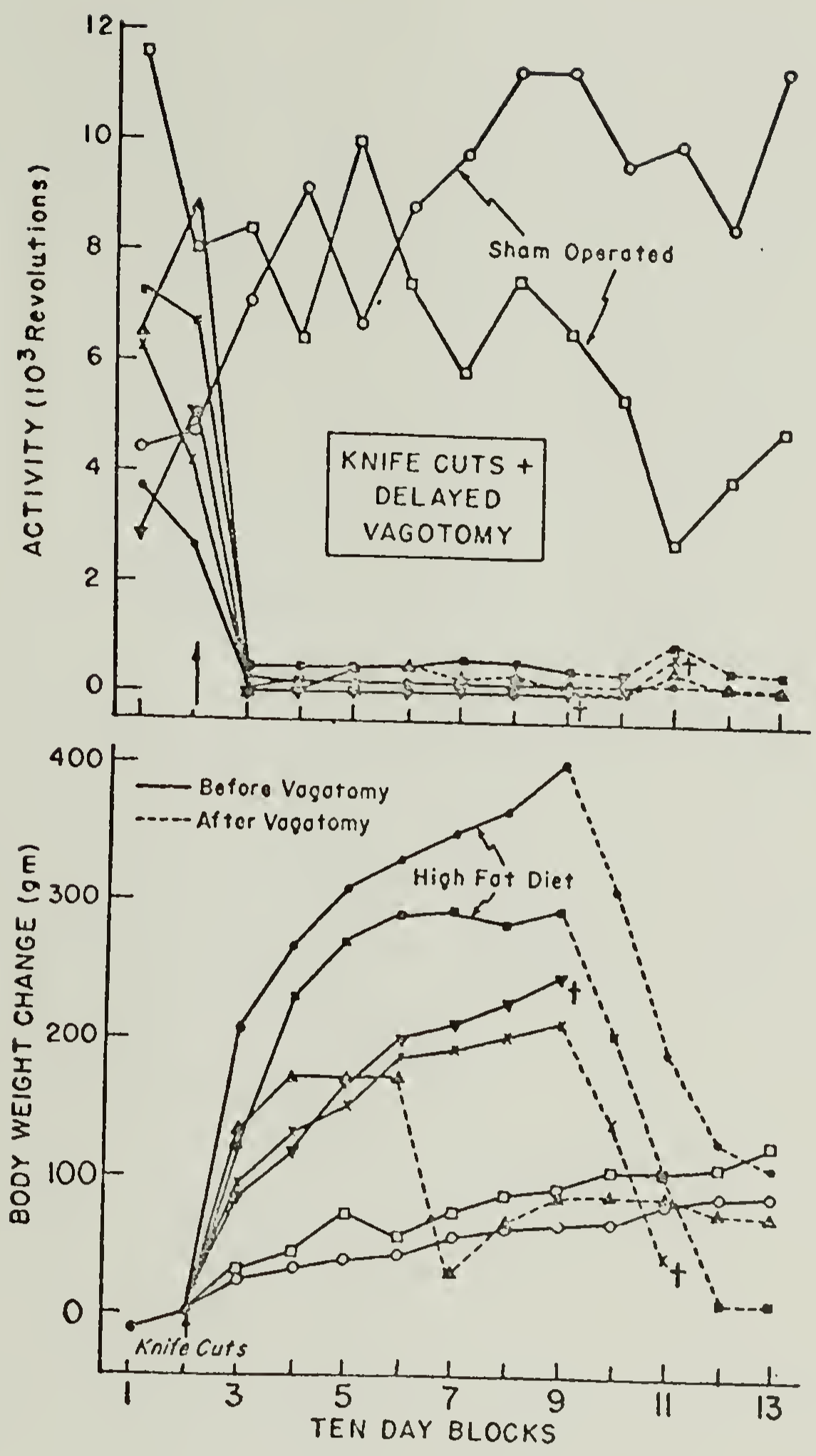

Figure 3. The activity and body weight data from individual animals with knife cuts followed by vagotomy at intervals of 40 or 70 days subsequent to the knife cuts. Dotted line indicates post vagotomy data. Two rats were on a high fat diet and three rats were on a pellet diet. crosses indicate fatalities. 


\section{$\underline{\text { References }}$}

Bash, K. W. An investigation into a possible organic basis for the hunger drive. Journal of Comparative and Physiological Psychology, 1939, 28, 109-136.

Bergstrom, J., L. Hermansen, E. Hultman, and B. Saltin. Diet, muscle glycogen and physical performance. Acta Physiologica Scandinavica, $1967,71,140$.

Bernardis, L. L. and L. A. Frohman. Effect of lesion size in the ventromedial hypothalamus on growth hormone and insulin levels in the weanling rat. Neuroendocrinology, $1970, \underline{6}, 319-328$.

Brooks, C. MCC: The relative importance of changes in activity in the development of experimentally produced obesity in the rat. American Journal of Physiology,
1946, 147, 708-716.

Campbell, B. A. and H. C. Fibiger. Effects of insulin on spontaneous activity during food deprivation. Jour-

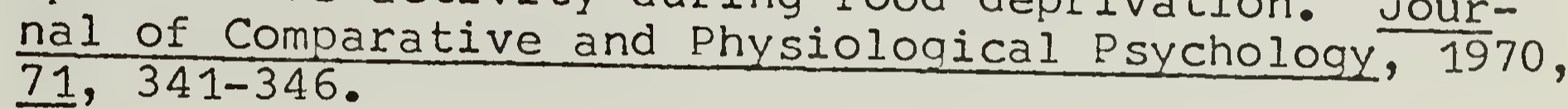

Colvin, G. B. and C. H. Sawyer. Induction of running activity by intracerebral implants of estrogen in ovariectomized rats. Neuroentocrinology, 1969, 4, 309320 .

Friedman, M. I. and E. M. Stricker. The physiological psychology of hunger: a physiological perspective. Psychological Review, 1976, 83, 409-431.

Gale, S. K. and A. Sclafani. Comparison of ovarian and hypothalamic obesity syndromes in the female rat: effects of diet palatability on food intake and body weight. Journal of Comparative and Physiological Psychology, 1977, 91, 381-392.

Gladfelter, W. E. and J. R. Brobeck. Decreased spontaneous locomotor activity in the rat induced by hypothalamic lesions. American Journal of Physiology, 1962, 203, 811-817. 
Gold, R. M. Hypothalamic hyperphagia produced by parasagittal knife cuts. Physiology and Behavior, 1970 ,
, 23-25.

Gold, R. M., A. P. Jones, P. E. Sawchenko, and G. Kapatos. Paraventricular area: critical focus of a longitudinal neurocircuitry mediating food intake. Physiology and Behavior, 1977, 18, 1111-1119.

Gold, R. M. and G. Kapatos. Delayed hyperphagia and increased body length after hypothalamic knife cuts in weanling rats. Journal of Comparative and Physiolog-

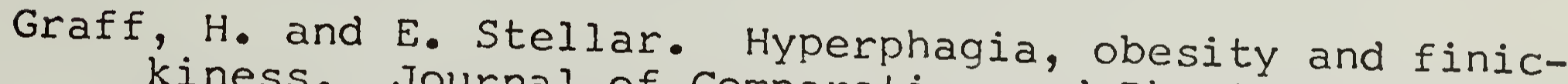
chology, Journal of Comparative and Physiological Psy-

Greer, M. A. The effect of progesterone on persistent vaginal estrus produced by hypothalamic lesions in the rat. Endocrinology, 1953, 53, 380-390.

Grossman, S. P. The VMH: center for affective reactions, satiety, or both? Physiology and Behavior, 1966, 1

Grossman, S. P. Aggression, avoidance, and reaction to novel environments in female rats with ventromedial hypothalamic lesions. Journal of Comparative and thysiological Psychology, 1972, 78, 274-283.

Hales, C. N. and G. C. Kennedy. Plasma glucose, non-esterified fatty acid and insulin concentrations in hypothalamic hyperphagic rats. Journal of Biochemistry, 1964, 90, 620-624.

Han, P. W. and L. A. Frohman. Hyperinsulinemia in tubefed hypophysectomized rats bearing hypothalamic lesions. American Journal of Physiology, 1970, 219 , 1632-1636.

Hennessy, J. W. and S. P. Grossman. Overeating and obesity produced by interruption of the caudal connections of the hypothalamus: evidence of hormonal and metabolic disruption. Physiology and Behavior, 1976, 17, 103-109. 


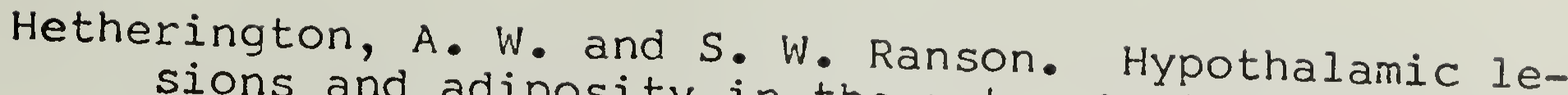
sions and adiposity in the rat. Anatomical Record, 1940, 78, 149-172.

Hetherington, A. W. and S. W. Ranson. The spontaneous activity and food intake of rats with hypothalamic lesions. American Journal of Physiology, 1942, 136,

Hustvedt, B. E. and A. L $\phi v \phi$. Correlation between hyperinsulinemia and hyperphagia in rats with ventromedial hypothalamic lesions. Acta Physiologica Scandinavica,

Inoue, S. and G. A. Bray. The effects of subdiaphragmatic vagotomy in rats with ventromedial hypothalamic obesity. Endocrinology, 1977, 100, 108-114.

Kakolewski, J. W., V. C. Cox and E. S. Valenstein. Sex differences in body weight changes following gonadectomy of rats. Psychological Reports, 1968, 22, 547-
554 .

Kennedy, G. C. and J. Mitra. Hypothalamic control of energy balance and the reproductive cycle in the rat. Journal of Physiology, 1963, 166, 395-407.

Kennedy, G. C. and R. A. Parker. The islets of Langerhans in rats with hypothalamic obesity. Lancet, 1963, 2 ,

Kennedy, G. C. Hypothalamic control of the endocrine and behavioral changes associated with oestrus in the rat. Journal of Physiology, 1964, 172, 383-392.

May, K. K. and J. R. Beaton. Hyperphagia in the insulin treated rat. Proceedings of the Society for Experimental Biology and Medicine, 1968, 127, 1201-1204.

Messing, R. B. and B. A. Campbell. Effect of non-nutritive bulk and food deprivation on wheel running activity of vagotomized rats. Journal of Comparative and Physiological Psychology, 1971, 77, 403-405. 
Panksepp, J., A. Pollack, K. Krost, R. Meeker and M. Ritter. Feeding in response to repeated protamine zinc 14, 487-493.

Paxinos, G. The hypothalamus: neural systems involved in feeding, irritability, aggression and copulation in male rats. Journal of Comparative and Physiological Psychology, 1974, 87, 110-119.

Porte, D., L. Girardier, J. Seydoux, Y. Kanazawa, and J. Pasternak. Neural regulation of insulin secretion in the dog. Journal of Clinical Investigations, 1973 ,

Powley, T. L. and C. A. Opsahl. Ventromedial hypothalamic obesity abolished by subdiaphragmatic vagotomy. American Journal of Physiology, 1974, 226, 25-33.

Ralph, T. L. and P. E. Sawchenko. Differential effects of lateral and ventrolmedial hypothalamic lesions on gastrointestinal transit in the rat. Brain Research Bulletin, 1978, 3 , 11-14.

Ridley, P. T. and F. P. Brooks. Alteration in gastric secretion following hypothalamic lesions producing hyperphagia. American Journal of Physiology, 1965,

Sawchenko, P. E., R. Eng, R. M. Gold, and E. L. Simson. Effects of selective subdiaphragmatic vagotomy on knife cut induced hypothalamic hyperphagia. Paper presented at the $6^{\text {th }}$ International Conference on the Physiology of Food and Fluid Intake, Paris, 1977 .

Sawchenko, P. E., R. M. Gold and P. A. Ferrazano. Abolition by selective vagotomy of the influence of water temperature on water intake: mediation via enhanced gastric clearance. Physiology and Behavior, $1977 \mathrm{~b}$, 18, 1055-1059.

Sclafani, A. Neural Pathways involved in the ventromedial hypothalamic lesion syndrome in the rat. Journal of Comparative and Physiological Psychology, 1971, 77, 70-76. 
Sclafani, A., J. Belluzzi and S. P. Grossman. Effects of lesions in the hypothalamus and amygdala on feeding physiological Psychology, 1970, 72, 394-403.

Sclafani, A. and S. P. Grossman. Reactivity of hyperphagic and normal rats to quinine and electric shock. Journal of Combarative and Physiological Psychology,

Sclafani, A., D. Springer and L. Kluge. Effects of quinine adulterated diets on the food intake and body weight of obese and non-obese hypothalamic hyperphagic rats. Physiology and Behavior, 1976, 16, 631-
640 .

Spence, J. T., B. J. Underwood, C. P. Duncan and J. W. Cotton. Elementary Statistics. New York: AppletonCentury-Crofts, 1968, pp. 108-112.

Storlien, L. H. and D. J. Albert. The effect of VMH lesions, lateral cuts, and anterior cuts on food intake, activity level, food motivation, and reactivity to task. Physiology and Behavior, 1972, 9, 191-197.

Tannenbaum, G. A., G. Paxinos and D. Bindra. Metabolic and endocrine aspects of the VMH syndrome in the rat. Journal of Comparative and Physiological Psychology, 1957, 50, 486-490.

Teitelbaum, P. Random and food directed activity in hyperphagic and normal rats. Journal of Comparative and Physiological Psychology, 1957, 50, 486-490.

Wade, G. N. Sex hormones, regulatory behaviors, and body weight. Advances in the Study of Behavior, 1976, 6 ,

Wang, G. H. The relation between "spontaneous" activity and oestrus cycle in the white rat. Comparative Psychological Monographs, 1923, 2(6), 1-27. 



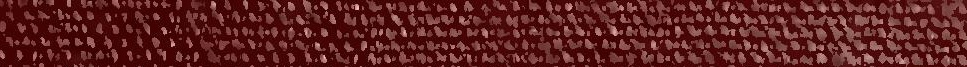

